\title{
Theory for the Public Good? Social Capital Theory in Social Work Education
}

\author{
MaryAnn Overcamp-Martini
}

\begin{abstract}
As a concept, social capital is both relatively recent and highly controversial. This analysis overviews the history of social capital theory and the three main theoretical frameworks related to the concept. The components of social capital are discussed, as well as the controversy over its conceptualization. A review of recent studies is provided, particularly in the relationship between social capital and mental health. The article concludes with a discussion regarding the heuristic usefulness of social capital theory in the human behavior and social environment sequence in social work education, opening discourse in civic engagement and participation, collectivity, and the value of social networking.
\end{abstract}

Keywords: Social capital theory, social work education, human behavior and the social environment, social capital and mental health, social networks, social work and civic participation

$\mathrm{I}$

$\mathrm{t}$ is rare enough that there is enthusiasm around a term or theory used in the macro Human Behavior and the Social Environment curriculum, particularly at this time in social work history. Does it matter that we join groups or associations? Does the number of television sets in the nation actually affect whether I can get help when my car stalls in traffic? Is there something called "social capital," and if so, do I really have to be more of a joiner to make more of it? Does it matter, in other words, whether or not we are "bowling alone" as Robert Putnam (2000) suggests?

The concept of social capital is a relatively recent one, with the development of theory in an unsettled and underdeveloped state. While potentially very relevant as theory for students in social work, particularly in the sequence of studies regarding human behavior and the social environment (HBSE), its usefulness may remain limited due to its seeming endless elasticity. This analysis will provide an overview of the history of social capital theory, which, in the social sciences, is generally agreed to at least mean "...social networks that can be activated" (Wall, Ferrazzi, \& Schryer, 1998, p. 304). Implicit in much of the discussion is that social capital at

MaryAnn Overcamp-Martini, Ph.D. is assistant professor, School of Social Work, University of Nevada, Las Vegas, Las Vegas, NV 89154-5032.

Copyright $^{\bullet} 2007$ Advances in Social Work Vol. 8 No. 1 (Spring 2007) 196-207. Indiana University School of Social Work. 
some level represents a public good to be encouraged. Because of this seeming prejudice toward the public good, scrutiny of the term and its accompanying theoretical base is especially important.

\section{HISTORY OF THE TERM}

The fact that six authors sporadically used the term "social capital" over a period of approximately 70 years in the $20^{\text {th }}$ century may be a foreshadowing of the widely diverse uses of the term today. Putnam (2000) names the six early users of "social capital” as: Hanifan (1916), Canadian sociologists (1950s), Jacobs (1961), Loury (1970s) and Bourdieu (1980s), and Schlicht (1980s). The interests of these authors ranged from education to sociology to economics, but with all focusing use of the term "social capital" on the importance of social relationships, apparently without knowledge of the others' work. Generally, credit is given to Jacobs (1961) for first use of the term:

If self-government is to work, underlying any float of population must be a continuity of people who have forged neighborhood networks. These networks are a city's irreplaceable social capital. Whenever the capital is lost, from whatever cause, the income from it disappears, never to return until and unless new capital is slowly and chancily accumulated (p. 138)

As a 1960s urbanist critiquing the governmental practices of urban renewal, Jacobs deplored the imposition of governmental destruction and reconstruction of depressed urban areas, advocating instead the development of dense urban communities similar to Greenwich Village in New York City. Interestingly, governments seem to be coming full circle on that issue.

Bourdieu (1986), Coleman (1988), and Putnam (1993, 2000) represent the three main developments of theoretical frameworks for social capital (Wall et al., 1998). Bourdieu's (1986) original theoretical work described the term "capital" as having three forms: economic, cultural, and social. He saw social capital as the property of the individual, such that someone with social "connections" could convert his or her connections into economic advantage or capital. He posited that social capital could also be institutionalized into the fabric of society in ways such as the titling of the noble class or, for that matter, acceptance at a better university due to the social capital of a prestigious high school's name.

Coleman (1988) is credited with shaping a different theoretical framework for social capital. Attempting to forge an alternative to an economic ("undersocialized") purpose of social action as rational self-interest and a sociological ("oversocialized") purpose of social action as determined by social norms and obligations, Coleman developed a concept of social capital to include components of both. Given the economic emphasis on physical capital (tools and equipment) and human capital (skills and capabilities), Coleman brought forward the term social capital to discuss the "something more" of social action, a value-added dimension. All capital being productive, social capital made human capital more so, suggesting that a group "within which there is extensive trustworthiness and extensive trust is able to accomplish much more than a comparable group without that 
trustworthiness and trust" (p. S101). Coleman's work developed out of a study of the interlocking expectations of adult networks on children-an intergenerational closure of social networks-where high school graduation rate outcomes were significantly higher for those in the religiously-affiliated private high schools than in public schools or non-religious private schools.

Whereas Bourdieu had focused social capital at the individual level, Coleman placed it at the family and community level. Putnam (1993) drew more directly from Coleman's work, placing the level of analysis at the community or regional level (Wall et al., 1998). Putnam (1993) initially introduced his interest in social capital through a study of local governmental effectiveness in Italy. He later brought his concept of social capital to the public fore with the publication of Bowling Alone, supporting a more expansive theory of social capital as based on civic participation, a property of a group.

It was the metaphor of "bowling alone" that engaged the public discussion of social capital. Is the response to Putnam's book a visceral national reaction to the "malaise" in the nation? According to Lehman (1996), this is the case. Lehman contends that Putnam's book "struck a nerve," because it provided a rationale for a growing sense that "the quality of our society at the everyday level has deteriorated severely" (p. 4). The bottom line of Putnam's thesis is that civic engagement has been in rapid decline in the United States since the 1960s, largely as a result of television privatizing our leisure, in essence causing our associations with one other in voluntary groups to suffer. Whether this is true or not-and Lehmann suggests not-is the subject of some lively academic discussions. Lehmann contends that the associational groupings that Putnam studied have simply been replaced by newer groupings of people and that our civic engagement remains largely intact. Regardless, the discussion itself points to re-visiting the issues of individualism and collectivity.

The movement toward individualism has been noted as a major trend in social organization since at least the $18^{\text {th }}$ century and was forged by related movements in political philosophy and economic theory. Individual rights have subsequently become embedded in "sociocultural arrangements that encourage and legitimate the autonomy, dignity, and equality of individuals” (Horwitz \& Mullis, 1998, p. 119). In reference to social action, however, Coleman (1990) called it a "broadly perpetuated fiction in modern society" (p 300) that social action is independent action by independent individuals working solely from self-interest, rather than actions influenced by relations among people. Thus, the corrective construction of the term "social capital."

Much passion is fashioned into the current discussion surrounding the term and beginning theory of social capital. As a brief taste of the intensity of the discourse, Greeley (1997) suggested the work of others to be "pop social science" (p. 587), while Greeley, himself, used Coleman's (1988) definition of social capital to illustrate the importance of certain social structures in creating social capital. Putnam's arguments were supposedly "devastated" by Ladd (Greeley, 1997, p. 587), while Ladd (1996) admitted that, while he would prefer not to argue with Putnam, he had little choice, "... it's testimony to the prominence of his work that it's impossible to avoid such an argument” (p. 1). The data debate has continued 
since. Perhaps it will turn out that our civic engagement has remained steady, but that changes in the form of that engagement will still mean at least a temporary decrease in social capital. If people are switching types of engagement, they may actually be as actively involved as ever (Greeley, 1997). However, the new activity will slowly construct new ties that begin to interconnect and overlap, while old ties are likely to loosen and unweave. Putnam (2000) discussed social capital in this country until recently as cyclical; however, perhaps the loss he described in social capital is more of a cycle caught up in these changes than a permanent issue.

That Putnam's work became a part of the popular and political culture of our times is itself no small matter and represents the importance of its recognition in the social work curriculum. Although the study of social capital began in the literature on urban and community studies, it has moved into such diverse disciplines as education, health, urban poverty, unemployment, criminology, sociology, social philosophy, public policy, international development, economics, trust in society, experimental psychology, sociology, political science, and economics. On the other hand, it is exactly this popularity and over-generalization of the theory of social capital that has initiated the current onslaught of criticism (Wall et al., 1998). The theory and research currently seem boundary-less. The advice of Wall et al. (1998) is worth noting:

...there is a point where diverse interpretations create more confusion than clarity. Social capital is on the threshold of being used so widely and in such divergent ways that its power as a concept is weakened ( $\mathrm{p}$. 319).

Confusion over the boundary-expansiveness of the theory should not be allowed to deflate all the energy this concept is generating. Abandoning the concept of social capital before it is fully pursued would be unfortunate, rare as it is to obtain the benefits of the attention of the larger non-academic community, while pursuing a potential lead in the social sciences. Political and popular focus on macrolevel theory may provide some impetus for political advocacy of governmental investment in community. Coming as it does at a time when traditional public policy agenda-setting techniques are similarly changing in the light of the electronic communications revolution, the need to better understand the building of networks is particularly timely. Fortunately, the next steps in further research of social capital theory have begun. Perhaps the greatest disagreement lies in the definitions of social capital, beginning with the determination whether social capital is the property of the individual or the property of the group.

\section{Individual Social Capital}

Originally, social capital was seen more generally as the property of the individual; in other words, it was a good that the individual could access as a resource (Bourdieu, 1986; Coleman, 1988, 1990). For example, the individual could derive benefit from contacts with friends of friends who had information about a potential job opportunity (a private good) or the individual could benefit from a support group for cancer survivors at a local hospital (a public good). It was the differential access that represented the extent or amount of social capital that 
belonged to a person. In either case, the individual benefits from phenomena we already term as social supports and social networks (McKenzie \& Harpham, 2006).

\section{Ecological Social Capital}

In Putnam's study of government in Italy (1993), for instance, he concluded that our tendency to contrast the ability of government and business to solve social problems ignored the factor that added something extra to each-that "both states and markets operate more efficiently in civic settings" (p. 181). According to Putnam, the horizontal relationships built by groups engaged in society build a thicker web of social trust that everyone benefits from, making the outcome (social capital) a property of the group. The most accepted definition for ecological social capital is currently that of Putnam (1993), and it refers to "features of social organization, such as trust, norms, and networks, that can improve the efficiency of society by facilitating coordinated actions" (p. 167). Of importance are the number and density of community networks, civic engagement and participation, reciprocity and norms of cooperation, and the building of personal and social trust (Putnam, 1993, 1995, 2000). The assumption is that the problems of society could be resolved by increasing social capital.

\section{Components of Social Capital}

Putnam (1995) concluded a study on Italian governments with the idea that "the performance of government and other social institutions is powerfully influenced by citizen engagement in community affairs," an engagement he termed "social capital" (p. 664). For this, Putnam drew on Coleman's (1990) discussion, developing the idea of social capital as "features of social life-networks, norms, and trust-that enable participants to act together more effectively to pursue shared objectives" (p. 664-665). Clearly, it is the building of relationships upon which social capital is dependent, not simply goal-directed actions and their outcomes. According to Putnam, relationships and trust build on each other, therefore, associating with others leads to a more trusting society.

The main components seem to have achieved some general acceptance as such: trust, networks, and norms of reciprocity between and within groups and institutions. Trust in society has come under increasing scientific and popular scrutiny, apparently, in the past few decades, as a result of the perception of a decline in trust in society. Again, the impact of individualism on our society seems to be at least on the edge of people's thinking: what is happening to this town, this country, this world? People will say that they do not feel as safe, as trusting. Attempting to address the risk of dealing with untrustworthiness in relationships, institutions, and society has led to a resurgence of trust in this study (Cook, 2001).

Personal trust is reinforced by the actions of someone who is found to be trustworthy, someone who does what is expected of them in response to an action, fulfilling the obligation invested in that interpersonal exchange. At the most basic level, these transactions involve a specific reciprocity, a version of "I'll do this for you if you do that for me" (Putnam, 2000, p. 20). In small communities where people are familiar with each other and know more of what to expect from each other (and are likely to remain in relationships with each other with the concomitant consequences), personal trust becomes social trust. The familiarity breeds what 
Putnam (2000) calls "thick" trust, "trust embedded in personal relations that are strong, frequent, and nested in wider networks" (p. 136). Where this thick trust continues to be reinforced, wider networks reach farther into society, creating a more trusting society, which, in turn, results in a greater efficiency where each transaction does not have to be negotiated separately. Things function more smoothly, with less friction and the weighing of costs. However, this trust is different from that built on a personal relationship and specific reciprocity. As it reaches out further from the trust-based exchange of personal relationships, people may expect reciprocity on a different basis: "I'll do this for you now, without expecting anything immediately in return and perhaps without even knowing you, confident that down the road you or someone else will return the favor" (p. 134). Called "generalized reciprocity," this trust is called "thin trust" in the further reaches of the network, and it is Putnam (2000) who suggests that it is this thin trust that can make a larger society function more efficiently. So, it is social trust, these norms of reciprocity, and the interconnectedness of social networks, that are the building blocks of social capital theory.

As scholars have pursued definitions of social capital, they have identified different dimensions: structural/cognitive, bonding/bridging, and horizontal/vertical. In addition to the question of whether social capital is the property of individuals or groups, these dimensions represent some general agreement in this unsettled theoretical discussion (McKenzie \& Harpham, 2006).

\section{Structural/Cognitive}

Structural social capital involves the "relationships, networks, associations, and institutions that link together people and groups" (McKenzie \& Harpham, 2006). These are somewhat measurable and analyzable units, such as groups, associations, networks, and linkages; this is the data that comprises much of Putnam's analysis of social capital. Reference to "collective moral resources"-the underlying values, the norms of reciprocity, and the civic ideas, such as altruism and civic responsibility—is considered cognitive social capital (McKenzie \& Harpham, 2006, p. 15).

\section{Bonding/Bridging}

Called "sociological superglue," (Putnam, 2000, p. 23), bonding social capital refers to that which bonds or holds groups together. The thick trust, strong norms of reciprocity, and social networks in bonding social capital are focused on a particular group. The boundaries of the group are clearly defined and the networks closed, so that the social capital is exclusive and inward-focused, with a strong sense of group identity and loyalty. Bonding social capital maintains and reproduces itself (Lin, 1999). Although Putnam (2000) uses the idea of social capital as inextricably linked to civic engagement and thus is generally seen as a public good, neither Putnam nor other authors assume that only positive results will accrue from bonding social capital. Usually, examples of bonding not noted as a public good are groups, such as the Ku Klux Klan.

Bridging social capital is "sociological WD-40" (Putnam, 2000, p. 23). While bonding social capital holds a group together, bridging social capital focuses on linking to other groups and external resources. It is thought of as inclusive, finding 
commonalities with those outside the closer group, and pulling groups together in the social fabric. In contrast to bonding, which brings a group in closer relationship, bridging "greases the wheels" between groups, lowering the perception of difference and separation of interests. According to Putnam (2000), bridging social capital may be more important to study than bonding, since it stretches relationships and thus social trust into more layers of society ("thin" trust), interconnecting networks, and producing greater ease in social relationships. Bridging social capital may provide for information diffusion, access to resources, and the broadening of our personal identification and trust. It has also been judged as the more fragile of these types, as it stretches outward (McKenzie \& Harpham, 2006).

\section{Horizontal/Vertical}

Critics of Putnam's $(1993,2000)$ framework of social capital as a solution to social problems point to the lack of attention to hierarchical class inequalities and the potential of social groups to increase their command over the benefits of inequality, using social capital as a means for social control (Wall et al., 1998). Earlier formulations of the definition of social capital also seemed to suggest to some scholars that neighborhoods and communities were being told to build their own social capital-that government could not do anything for them, thus, as providing an "excuse" for a de-politization of responses to poverty (Foley \& Edwards, 1997). Critiqued as institutionalizing inequity and excusing public neglect brought about a further clarification of its dimensions.

The dimension of social capital focusing on the horizontal and vertical nature of relationships responds to these critiques. Out of this developed an understanding of horizontal social capital, then defined to consider the social capital between people in similar social strata. Earlier formulations fell within horizontal social capital. Vertical social capital, on the other hand, delineates linking, or the degree of integration, between people in different social strata of society. Those in lower strata can influence policy and access resources through relationships with those above them; whereas, those with more power and status have a way to dispense resources downward out of self-interest, charity, or justice (McKenzie \& Harpham, 2006). Perhaps we could call this sociological "chutes and ladders."

\section{REVIEW OF EMPIRICAL STUDIES}

While social capital is an engaging concept, it would have to be placed among the many HBSE theories without either an accepted operationalization or a solid empirical base. There does seem to be general agreement that the term social capital pulls together knowledge and research in three areas: trust, norms of reciprocity, and networks (McKenzie \& Harpham, 2006). For instance, social capital research builds on a renewed interest in the concept of social trust, a topic that resurfaced in the 1990s. The literature on social trust spans from psychological trust in another person, to social trust among groups, into the role of trust in networks, organizations, and institutions (Cook, 2001). Yet, most studies measure generalized trust using the same simple question, "do you think people in general can be trusted?" (De Silva, 2006, p. 50). Building on the concept of generalized trust are norms of reciprocity and networks, again shifting from the micro to the macro, and from cognitive social capital to structural social capital. Analyzing the state of cur- 
rent research in social capital and mental health, for instance, De Silva (2006) reviewed 28 studies, finding different aspects of social capital being measured, including cognitive social capital, structural social capital, family social capital, social capital at organizational and community levels, and neighborhood safety and disorder issues.

There have been three general perspectives on the definition of social capital in regard to the level of society it is applied to, broadly stretching the spectrum between the individual and the ecological. Generally, application in theory is made to levels beyond the individual, defining social capital as occurring in relationships within and between groups, thereby making it the "property of groups" (McKenzie, Whitley, \& Weich, 2002); yet, the feasibility of measurement has frequently led to an aggregation of the individual perspectives on the level of social capital they experience. In De Silva's review (2006), 21 of 28 selected studies measured social capital at the individual level, while only eight measured social capital at the ecological level either solely or in both categories. Therefore, while conceptualized in mezzo or macro levels, measurement generally occurred at the individual level. The question that has festered in these discussions has been whether that is a valid approach to measurement, or whether it measures an individual's ability to access social support and social networks, which is better seen as a property of individuals (McKenzie \& Harpham, 2006; Bourdieu, 1986). Recommending the co-existence of these approaches, De Silva (2006) suggests that the point of convergence exists in the value of social relationships:

Indeed, it seems that research into the two streams is so entrenched that it would be naïve to assume that either one can be ignored. However, taking a holistic view of social capital as the "value" of social relationships at any level allows the two streams not only to coexist but also to complement each other. Individual social capital considers direct relationships with a network (i.e., the impact of an individual participating in or perceiving a network), while ecological social capital considers the indirect relationships (i.e., the impact of networks irrespective of participation). For example, effective community networks that prevent the closure of a local hospital benefit everyone who depends on that hospital, not only those people involved in campaigning against the closure. As it is not necessary to be part of the campaign group to benefit from its actions, this is an example of an indirect relationship. However, there may also be an additional impact on those involved personally in the group (direct effects), with positive effects such as feelings of self-worth and negative effects such as time and emotional investment (p. 44).

Thus, this third perspective suggests that social capital, as a resource embedded in the relationship between individuals while being subject to access by the individual, is actually a property of relationship (De Silva, 2006).

Pursuant to the difficulties in defining social capital has been, of course, the difficulties of operationalizing its components. How do we actually measure social capital? The response to this question thus far has been to measure it indirectly. For example, using the dimension of structural social capital is a feasible way to 
study social capital, since it can be undertaken through the quantitative analysis of indicators, such as participation in civic groups and associations. Yet, again, problems surface in the mixed use of terms, such as "civic participation," which is widely used to describe "engagement in public affairs" and "membership in civic groups" (De Silva, 2006). Due to the diffusion and popularity of Putnam's (2000) work, Putnam's preference for measuring the membership has often been accepted as the preferred definition, with much of the literature focused in the direction of challenging his results.

Honing in on an area of special interest to social workers will demonstrate challenges to the research. For example, research regarding social capital and mental health may be fruitful to consider. As background, McKenzie (2006a) offers three important questions that social workers would also want answered:

- Can social capital prevent mental illness?

- Can the lack of social capital cause mental illness?

- Does the level and/or type of social capital in an area have an impact on the rate of mental illness?

Given that mental health/illness studies involve addressing the complexity of the intervening variables of risk and preventive factors, McKenzie notes that, what little longitudinal research has been done has been inconclusive in demonstrating causation. Whereas studies have demonstrated correlations between different aspects of social capital and a variety of mental illnesses, the pathways of causation through the intervening variables have not been researched.

De Silva (2006) also noted that more recent theory conceptualizes social capital as multidimensional, although much of the research focuses on unidimensional measurements, creating additional challenges in research, such as the unequal treatment of dimensions and the question of the validity of combining different measures and aspects of social capital. Alternative approaches to studying social capital and mental health support increasing the level of sophistication in this line of research. McKenzie (2006a) suggests the use of speculative models of association for research into social capital and mental health. De Silva (2006) recommends a number of refinements in research, including the increased use of longitudinal methods, the psychometric validation of measures, and analysis through statistical modeling using multi-level techniques. Qualitative and mixed methodologies are also recommended, especially to develop the conceptualization of social capital. De Silva also suggests that our concept of community may need some updating, considering that we most often place community in a geographical context when we have entered a non-spatial relationship with each other through electronic communications. The future of research will involve the study of non-spatial communities to social capital and the connections between all types of communities and the individual.

Yet, despite all these difficulties, several findings have begun to emerge from studies of social capital and mental health. McKenzie (2006b) describes three:

- Areas with higher levels of social capital are associated with social environments with fewer risks of mental health. 
- Social capital reflects facilitative behavior of residents that produces social supports and safety nets that buffer the effects of life events on mental health.

- Neighborhoods with high levels of certain types of social capital-for instance, collective efficacy—are better able to acquire and hold on to educational, health and housing resources that are linked to mental health. (p. 156).

There are also findings that relate more directly to practice with individuals who have serious mental illness and social capital. For this information to be useful to social work practice in mental illness, we need knowledge of the differential and negative effects of social capital, as well. For instance, longitudinal studies have shown social capital to be a protective factor in mental health, as noted above. However, as De Silva (2006) points out, the specific encouragement of group or civic participation, while conceptualized as positive for all groups in a democratic society, can lead to negative outcomes in mental health, where that encouragement actually can be experienced as increased stress by the individual, a known risk factor in mental illness.

Relatedly, the theory base for social capital generally directs us to think of social capital as a social good, rather than potentially leading to both positive and negative outcomes; however, the De Silva (2006) review also showed that many studies have understandably framed social capital as value-neutral in their measures. Perhaps related to this, theory would be better moved to match its operationalization. Before embracing social capital theory, the social work profession needs a fuller understanding of any differential effects on individuals, groups, organizations, and communities.

\section{IMPLICATIONS FOR SOCIAL WORK}

Let's face it. Social capital is easier to teach than trying to bring de Tocqueville's enthusiasm for civic participation in democratic society into most classrooms today. The concept of social capital touches a frayed nerve in the classroom, just as it has in the public's imagination. Students begin assessing their own social networks and civic engagement without prodding. For Putnam, the bogeyman is the privatizing of leisure through television. For me, it may well be the electronic door device that allows me to slip my car into the garage against the advances of a talkative neighbor. My students agree with both and, at least briefly, they heap other ideas onto the bonfire of individualism; the change of pace from our daily lives can be exhilarating. Some of my students tell me that these discussions change them in small or large ways; they re-consider their lack of engagement. As prospective social workers, they appropriate more the need for macro engagement and interventions in their work.

Social capital theory enjoys other uses in the HBSE and social work curriculum. As our society moves increasingly toward an individualistic political culture (see Elazar, 1972) linked to a capitalistic economy, the assumption of the need or right for social work intervention at the mezzo and macro level has diminished. Stronger emphasis on a development of the religious and philosophical bases for 
social justice stances is helpful. Yet, to a great extent for some students and for all students to some extent, the link of macro theories of intervention to economic theory can also assist this process. Whereas individual social capital takes students to the literature on social support and social networks, ecological social capital theory suggests that a higher level of social capital makes for a more efficient society where each exchange need not be handled individually but is based on a higher level of social trust and norms of reciprocity (Putnam, 2000).

Coleman (1988) suggested social capital as an "aid toward making micro-tomacro transitions without elaborating the social structural details through which this occurs" (p. S101). It was precisely to offer social capital as a flag, to let the reader know that what was important in a particular situation lay in the social context: trust, norms or reciprocity, networks, and organization. As a heuristic tool alone, social capital theory can act as a doorway to other relevant concepts and theories, such as social trust and network analysis, which also lay just outside the boundaries of mainstream curricula. Unpacking the concept was then a secondary step available to the reader and researcher, alike. The availability of social capital in one context also signaled its potential availability for use in another context; for example, a group formed for one purpose could also be used to further a different purpose. The dimensions of social capital theory-bonding, bridging, linking-tie together discussions in many areas. Resources for the individual, building strong neighborhoods and communities, and developing policy networks for social and political action, to name a few. For example, when Bressers and O'Toole (1998) point out dimensions of policy networks, cohesion and interconnectedness come as no surprise to those already studied in similar dimensions. It never hurts to run into old friends in the curriculum.

Nevertheless, despite a decade of academic flurry surrounding social capital theory and the dynamism that social capital can raise in the classroom, a review of popular HBSE texts shows that reference to it has been minimal in HBSE curriculum resources. For example, in the popular Robbins, Chatterjee, \& Canda (2006) text, one of few to mention the theory at all, social capital theory is given but a scant paragraph in which it is briefly related to exchange and rational choice theory as a social resource obtainable by the individual. Its increasing popularity in social work is noted, with students encouraged to visit Putnam's (2000) work. Putnam's work, of course, was primarily developed ecologically as a property of the group, based on "neo-deTocquevillean" ideas of participatory democracy and civic ideals (Fried, 2002), a far cry from the theory base referenced. Thus, it would be fair to say that social capital theory has not yet found a solid niche in social work education. It is hopefully not overreaching to suggest that this review of social capital theory has helped to detect a place in the HBSE curriculum for a macro theory with enough energy that it might yet find its legs.

\section{References}

Bourdieu, P. (1986). The forms of social capital. In J. Richardson (Ed.), The handbook of theory and research for the sociology of education. NY: Greenwood Press. 
Bressers, H.T.A., \& O’Toole, L.J., Jr. (1998). The selection of policy instruments: A network-based perspective. Journal of Public Policy, 18(3), 213-239.

Coleman, J.S. (1988). Social capital in the creation of human capital. The American Journal of Sociology, 94(Supplement), S95-S120. Retrieved August 22, 2006, from JSTOR database.

Coleman, J.S. (1990). Foundations of social theory. Cambridge, MA: Belknap Press.

Cook, K.S. (2001). Trust in society. In K.S. Cook (Ed.), Trust in society (pp. xi-xxviii): Vol. 2. Russell Sage Foundation Series on Trust. NY: Russell Sage Foundation.

De Silva, M. (2006). Systematic review of the methods used in studies of social capital and mental health. In K. McKenzie \& T. Harpham (Eds.), Social capital and mental health (pp. 39-67). Philadelphia, PA: Jessica Kingsley Publishers.

Elazar, D. (1974). American federalism: A view from the states ( $2^{\text {nd }}$ ed.). NY: Crowell.

Foley, M.W., \& Edwards, B. (1997). Escape from politics? Social theory and the social capital debate. American Behavioral Scientist, 40(5), 550-561.

Fried, A. (2002). The strange disappearance of Alexis de Tocqueville in Putnam's analysis of social capital (pp. 21-49). In S. McLean, D.A. Schultz \& M.B. Steger (Eds.), Social capital: Critical perspectives on community and "Bowling Alone." NY: New York University Press.

Greeley, A. (1997). Coleman revisited: Religious structures as a source of social capital. American Behavioral Scientist, 40(5), 587-594.

Horwitz, A.V., \& Mullis, J.S. (1998). Individualism and its discontents: The response to the seriously mentally ill in late twentieth century America: The moral community. Sociological Focus, 31(2), 119-133.

Jacobs, J. (1961). The death and life of great American cities. London: Penguin.

Ladd, E.C. (1996). The data just don't show erosion of America's social capital. The Public Perspective, 7(4), $7-16$

Lemann, N. (1996). Kicking in groups. The Atlantic Monthly, 277(April). Retrieved August 8, 2006, from http://xroads.virginia.edu/ HYPER/detoc/assoc/kicking.html.

Lin, N. (1999). Building a network theory of social capital. Connections, 22(1), 28-51.

McKenzie, K. (2006a). Social risk, mental health and social capital. In K. McKenzie \& T. Harpham (Eds.), Social capital and mental health (pp. 24-38). Philadelphia, PA: Jessica Kingsley Publishers.

McKenzie, K. (2006b). The state of the art. In K. McKenzie \& T. Harpham (Eds.), Social capital and mental health (pp. 151-158). Philadelphia, PA: Jessica Kingsley Publishers.

McKenzie, K., \& Harpham, T. (2006). Meanings and uses of social capital in the mental health field. In K. McKenzie \& T. Harpham (Eds.), Social capital and mental health (pp. 11-23). Philadelphia, PA: Jessica Kingsley Publishers.

McKenzie, K., Whitley, R., \&Weich, S. (2002). Social capital and mental health. British Journal of Psychiatry, $181,280-283$.

Putnam, R.D. (1993). Making democracy work: Civic traditions in Italy. Princeton, NJ: Princeton University Press.

Putnam, R.D. (1995). Tuning in, tuning out: The strange disappearance of social capital in America. PS Political Science and Politics 28(4), 664-683. Retrieved January 9, 2007, from JSTOR database.

Putnam, R.D. (2000). Bowling alone: The collapse and revival of American community. New York: Simon and Schuster.

Robbins, S.P., Chatterjee, P., \& Canda, E.R. (2006). Contemporary human behavior theory: A critical perspective for social work ( $2^{\text {nd }}$ ed.). Boston, MA: Pearson.

Wall, E., Ferrazzi, C., \& Schryer, F. (1998). Getting the goods on social capital. Rural Sociology 63(2), 300-322.

\section{Author's Note:}

Address correspondence to: MaryAnn Overcamp-Martini, Ph.D., School of Social Work, University of Las Vegas, 4505 Maryland Parkway, Box 455032, Las Vegas, NV 89154-5032, USA. e-mail: mao.martini@univ.edu. 